\title{
Association between delayed initiation of adjuvant CMF or anthracycline-based chemotherapy and survival in breast cancer: a systematic review and meta-analysis
}

\author{
Ke-Da Yu ${ }^{*}$, Sheng Huang ${ }^{\dagger}$, Jia-Xin Zhang ${ }^{\dagger}$, Guang-Yu Liu and Zhi-Ming Shao*
}

\begin{abstract}
Background: Adjuvant chemotherapy (AC) improves survival among patients with operable breast cancer. However, the effect of delay in AC initiation on survival is unclear. We performed a systematic review and metaanalysis to determine the relationship between time to $A C$ and survival outcomes.

Methods: PubMed, EMBASE, Cochrane Database of Systematic Reviews, and Web-of-Science databases (between January-1 1978 and January-29, 2013) were searched for eligible studies. Hazard ratios (HRs) for overall survival (OS) and disease-free survival (DFS) from each study were converted to a regression coefficient ( $\beta$ ) corresponding to a continuous representation per 4-week delay of AC. Most used regimens of chemotherapy in included studies were CMF (cyclophosphamide, methotrexate, and fluorouracil) or anthracycline-based. Individual adjusted $\beta$ were combined using a fixed-effects or random-effects model depending on heterogeneity.

Results: We included 7 eligible studies with 9 independent analytical groups involving 34,097 patients, 1 prospective observational study, 2 secondary analyses in randomized trials (4 analytical groups), and 4 hospital-/population-based retrospective study. The overall meta-analysis demonstrated that a 4-week increase in time to AC was associated with a significant decrease in both $\mathrm{OS}(\mathrm{HR}=1.15 ; 95 \%$ confidence interval $[\mathrm{Cl}], 1.03-1.28$; random-effects model) and DFS ( $H R=1.16 ; 95 \% \mathrm{Cl}, 1.01-1.33$; fixed-effects model). One study caused a significant between-study heterogeneity for OS $\left(P<0.001 ; I^{2}=75.4 \%\right)$; after excluding that single study, there was no heterogeneity $\left(P=0.257 ; I^{2}=23.6 \%\right)$ and the HR was more significant $(H R=1.17 ; 95 \% \mathrm{Cl}, 1.12-1.22$; fixed-effects model). Each single study did not fundamentally influence the positive outcome and no evidence of publication bias was observed in OS.
\end{abstract}

Conclusions: Longer time to AC is probably associated with worse survival in breast cancer patients.

\section{Background}

Breast cancer is one of the most common cancers in women in both developed and developing countries. Several large clinical trials and meta-analysis of all the relevant randomized trials of adjuvant systemic therapy have consistently demonstrated that chemotherapy decreases $30-40 \%$ risk of breast cancer mortality versus those without chemotherapy [1]. Adjuvant chemotherapy $(\mathrm{AC})$ is routinely recommended to most of breast

\footnotetext{
* Correspondence: yukd@shca.org.cn; zhimingshao@yahoo.com

${ }^{\dagger}$ Equal contributors

Department of Breast Surgery, Cancer Center and Cancer Institute, Shanghai Medical College, Fudan University, 399 Ling-Ling Road, Shanghai 200032, People's Republic of China
}

cancer patients post surgeries. National Comprehensive Cancer Network guidelines (www.nccn.org) recommend patients with tumor larger than $1 \mathrm{~cm}$ or having involved nodes to receive AC; while St. Gallen consensus recommends patients with endocrine non- or less-responsive disease to undergo AC [2]. Clinically, $60-80 \%$ of breast cancer patients would ultimately receive $\mathrm{AC}$, but the optimal time from surgery to the start of chemotherapy is unclear albeit clinicians have used chemotherapy in breast cancer for more than a half century. Oncologists might suggest start of $\mathrm{AC}$ within 6 to 8 weeks after surgery based on a routine clinical assumption that AC should commence as soon as practical. Some clinicians might also harbor the assumption that chemotherapy

\section{Ciomed Central}


would have little or no adjuvant benefit beyond a delay of 3 months [3]. However, there is no direct evidence supporting either of these assumptions. Of note, in practice, not all patients could initiate $\mathrm{AC}$ in this time frame, and some have to face a delay in $\mathrm{AC}$ due to postoperative complications, personal decision of receiving $\mathrm{AC}$, comorbid conditions, or health-system logistic factors such as delays in referral or waiting times.

Time window of $\mathrm{AC}$ treatment remains an important issue. Regrettably, this issue has not been subjected to a randomized controlled clinical trial; nor is such trial likely to be undertaken due to its low operability, poor patient compliance, and potential ethical problems. Several retrospective studies [4-7], observational prospective studies [8], and retrospective analyses on clinical trial data $[9,10]$, have examined the impact of early and delayed initiation of AC on survival of breast cancer patients, but the results are inconsistent. To address this important gap, we undertook a systematic review of all the relevant literatures and performed a quantitative meta-analysis to assess the relationship between a delay in $\mathrm{AC}$ and survival in breast cancer.

\section{Methods}

\section{Literature search}

The literature search was conducted in the PubMed, EMBASE, Cochrane Database of Systematic Reviews, and Web-of-Science databases (between January-1 1978 and January-29 2013). Potentially relevant studies were identified using following keywords: "(Timing or time) and adjuvant and (chemotherapy or chemotherapeutic) and breast cancer and survival". The reference lists from relevant papers, especially from review articles, were checked to identify more studies unidentified in the original search. Online available abstracts of the annual meetings of the American Society of Clinical Oncology (2007-2011) were searched for newly completed studies. This systematic review and meta-analysis was planned, conducted, and reported in adherence to the standards of quality for reporting meta-analysis [11]. The basic procedure of meta-analysis was performed as described previously [12-14].

\section{Eligibility and validity of literature-based data}

The citations from the initial search were subsequently screened for eligibility. Studies included in the systematic review and meta-analysis should meet the following criteria: (1) All patients with operable primary breast cancer were treated with $\mathrm{AC}$, with documented time from surgery to initiation of AC. (2) The relationship between time interval from surgery to $\mathrm{AC}$ and patient outcomes in breast cancers was reported. The outcomes could be presented as disease-free survival (DFS), eventfree survival (EFS), relapse-free survival (RFS), or overall survival (OS). Hazard ratio (HR) with 95\% confidence intervals (CIs) (or sufficient data to calculate them) was reported. (3) To minimize the effect of confounding between comparison groups, only studies identified as "high validity" by the following criteria were included in the pooling analysis: first, the relevant prognostic factors were adequately described between comparator groups; second, either the comparison groups were balanced for the relevant prognostic factors, or the reported results were adjusted for other prognostic factors [13]. (4) Studies that used nonstandard forms of AC (e.g., perioperative, dose-dense, or neoadjuvant chemotherapy), or examined the effect of concurrent or sequencing of additional adjuvant therapies (e.g., endocrine therapy or radiotherapy) were excluded. (5) To reduce the effect of publication bias, all publish types either full-text article, correspondence, or meeting abstract were eligible. But studies should be published in English. Three reviewers (Y.K.D., H.S., and S.Z.M.) independently assessed studies for inclusion with disagreements resolved by consensus. The study quality was assessed using the 9-star Newcastle-Ottawa Scale (The Newcastle-Ottawa Scale for assessing the quality of nonrandomized studies in meta-analyses. Ottawa, Canada: Dept of Epidemiology and Community Medicine, University of Ottawa. http://www.ohri.ca/ programs/clinical_epidemiology/oxford.htm. Accessible on March-1, 2013).

\section{Estimating HR for adverse outcomes per 4-week delay in $A C$}

This step was mainly performed according to the procedure described previously with a few modifications $[13,14]$. Briefly, the measure of effect in all studies was a HR for OS and/or DFS. In most studies, EFS or RFS had the same or similar definition to DFS and thus was treated as DFS when appropriate. The eligible studies used disparate categorical representations of waiting time. To provide a common representation for synthesis of the results of individual studies, we converted the waiting time effect size to a regression coefficient ( $\beta$ ) and its standard error (SE) corresponding to a continuous representation per 4-week of delay. For the waiting time categories in each article, a central value was assigned to each category. For studies with 2 waiting time groups, since the authors defined the 2 groups as "before $n$ weeks (not delayed AC)" and "after $n$ weeks (delayed AC)", we treated the reference time level as $n / 2$ weeks and the exposure time level as $n / 2+n$ weeks. the weekly $\beta$ was calculated as $\ln (\mathrm{HR}) /(\mathrm{X} n-\mathrm{X} 0)$, and the corresponding SE of $\beta$ was calculated as (ln[upper of $95 \% \mathrm{CI}]-\ln [$ lower of $95 \% \mathrm{CI}]) /\left([\mathrm{X} n-\mathrm{X} 0]^{*} 1.96 \% 2\right)$, where $\mathrm{CI}$ is confidence interval, $\mathrm{X} n$ denotes exposure at $\mathrm{N}$ level by time (week), and $\mathrm{X} 0$ denotes exposure at reference time level. We transferred all time unit (day, week, or 
month) to "week" and " $\mathrm{N}$ " in the $\mathrm{X} n$ was assigned to the number of week. The value of 1.96 might change according to the significance level in each study. If only a P-value was provided, the SE was calculated as the "test-based" method: $\mathrm{SE}$ of $\ln (\mathrm{HR})=(\ln [\mathrm{HR}]) / \mathrm{Z}_{\mathrm{p}}$, where $\mathrm{Z}_{\mathrm{p}}$ is the value of a unitnormal test (e.g., $Z_{p}=1.96$ when $P=0.05$, 2-sided test). For the studies with more than 2 categories, the weighted least-squares linear regression of the $\ln (\mathrm{HR})$ on every exposure level in one study was used to estimate the summary $\beta$ as previously described $[15,16]$. The dependent variable for the regression was the log of each studyspecific HR, weighted by the inverse of its variance. The summary measures of HR per 4-week of delay from each study presented here can be interpreted as the incidence rate ratio for the outcome with each 4-week of additional waiting for $\mathrm{AC}$, which could be calculated by $e^{\beta^{*} 4}$. We made all the above calculations assuming a log linear relationship between HR and delayed time.

\section{Meta-analysis}

The adjusted regression coefficients from individual studies were combined using a fixed-effects or randomeffects model according to absence or presence of between-study heterogeneity, respectively. Q statistic and $\mathrm{I}^{2}$ were used to evaluate the statistical heterogeneity between studies [17]. Heterogeneity was considered as either a P-value $<0.05$ or $\mathrm{I}^{2}>25 \%$ [18]. The inverse variance was used to weight individual studies. We performed influence analysis (sensitivity analysis) by omitting each study to find the potential outliers. The potential publication bias was examined visually in a funnel plot of $\log (\mathrm{HR})$ against its $\mathrm{SE}$, and the degree of asymmetry was tested using Egger's test [19] $(\mathrm{P}<0.05$ considered to be statistically significant). All of the statistical analysis was performed using Stata v.10.0 (Stata Corporation, College Station, TX) and SPSS 17.0 (SPSS Inc, Chicago, IL). Two-sided $\mathrm{P}<0.05$ was considered statistically significant.

\section{Results}

The flow diagram of literature search is shown in Figure 1. The search strategy yielded 1,157 reports, of which 29 were potentially eligible after reviewing their abstracts. Twenty-one items were further excluded either because of a lack of data or because they did not meet the high validity criteria, leaving 7 eligible papers including 7 independent analytical groups for OS and 2 for DFS, respectively (Table 1). The studies were published between 1989 and 2013. There were 34,097 patients with primary breast cancer, with a range of sample size from 229 to 14,380 . Two studies (4 analytical groups) reported time to AC data as a secondary analysis within randomized controlled trials of chemotherapy treatment [9], 1 study was conducted

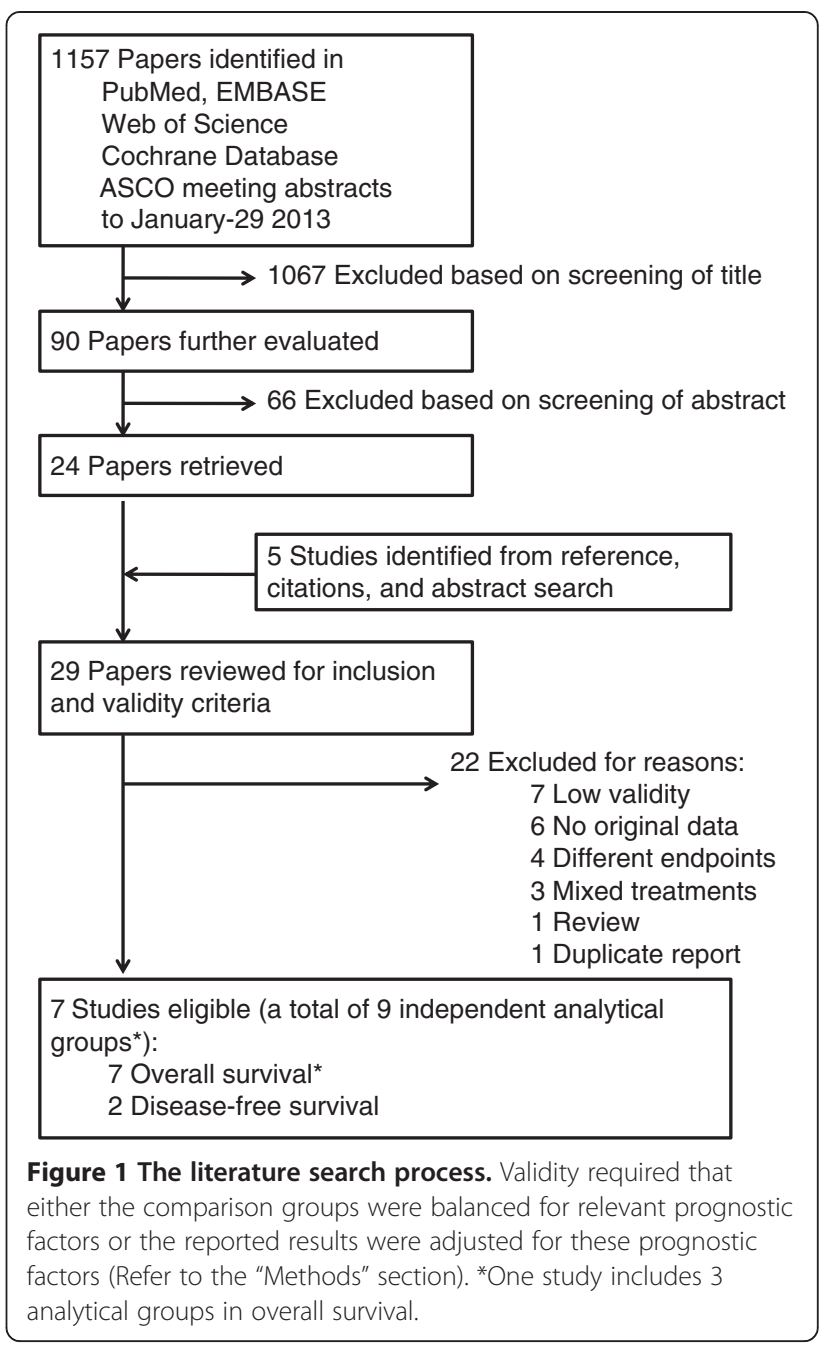

prospectively $[8,10]$, and the left 4 were retrospective investigations using hospital- or population-based data [5-7,20].

The HR results from individual eligible studies listed in Table 1 are plotted in Figure 2A, which shows the HRs for categorical representations of waiting time in the 7 studies for OS. The waiting times covered by the studies ranged from 2 to 12 weeks. This figure illustrates that HRs at different waiting time were similar and therefore supports conversion of HRs from categories to an HR for a continuous representation by waiting time. For each study, a single HR corresponding to the relative increase in mortality risk with each additional 4-week of waiting time was extracted (Figure 2B). For studies contrasting 2 waiting time categories, the line was the same as that presented in Figure 2A. For studies using more than 2 categories, the HR was estimated using metaregression. The 4-folds of slope of each line (by log converted $\mathrm{HR}$ ) in Figure 2B represented the log of final HR used in meta-analysis (i.e., HR per 4-week of delay). 
Table 1 Characteristics of eligible studies on waiting time to adjuvant chemotherapy and survival in breast cancer

\begin{tabular}{|c|c|c|c|c|c|c|c|c|c|c|c|c|}
\hline Source & $\begin{array}{l}\text { Place, data } \\
\text { type and } \\
\text { name }\end{array}$ & $\begin{array}{l}\text { Median } \\
\text { age, } \\
\text { year }\end{array}$ & $\begin{array}{l}\text { Menopausal } \\
\text { status }\end{array}$ & Stage & $\begin{array}{l}\text { Hormone } \\
\text { receptor- } \\
\text { positive } \\
(\%)\end{array}$ & Chemotherapy & $\begin{array}{l}\text { Median FU } \\
\text { Outcome and HR } \\
(95 \% \mathrm{Cl})\end{array}$ & $\begin{array}{l}\text { WT } \\
\text { categories }\end{array}$ & $\begin{array}{l}\text { Sample } \\
\text { size }\end{array}$ & $\begin{array}{l}\text { Additional } \\
\text { survival } \\
\text { data }\end{array}$ & $\begin{array}{l}\text { Study } \\
\text { quality** }\end{array}$ & $\begin{array}{l}\text { Adjustment for } \\
\text { covariates }\end{array}$ \\
\hline \multirow{3}{*}{$\begin{array}{l}\text { Pronzato et al } \\
\text { [8] } 1989\end{array}$} & \multirow[t]{3}{*}{ Italy (Pros.) } & \multirow{3}{*}{$\begin{array}{l}51 \text { yr } \\
\text { (range, } \\
27-70)\end{array}$} & \multirow[t]{3}{*}{ Mixed } & \multirow{3}{*}{$\begin{array}{l}\text { Operable } \\
(\mathrm{LN}+)\end{array}$} & \multirow[t]{3}{*}{ NR } & \multirow[t]{3}{*}{ CMF } & Median FU: 37 months & Total & 229 & 4-yr OS:78\% & \multirow[t]{3}{*}{7} & \multirow{3}{*}{$\begin{array}{l}\text { Age, nodes status, } \\
\text { menopausal status, } \\
\text { cycle number, } \\
\text { individual dose } \\
\text { intensity }\end{array}$} \\
\hline & & & & & & & Reference & $\leq 35$ days & 116 & 4-yr OS:88\% & & \\
\hline & & & & & & & OS, $2.61(1.26-5.39)$ & $>35$ days & 113 & 4-yr OS:69\% & & \\
\hline \multirow{3}{*}{$\begin{array}{l}\text { Colleoni et al. } \\
\text { [9] } 2000\end{array}$} & \multirow{3}{*}{$\begin{array}{l}\text { Multicenter } \\
\text { (CT, IBCSG) }\end{array}$} & \multirow{3}{*}{$\begin{array}{l}78 \% \mathrm{pts} \\
\geq 40 \mathrm{yr}\end{array}$} & \multirow[t]{3}{*}{ Pre. } & \multirow{3}{*}{$\begin{array}{l}\text { Operable } \\
(\mathrm{LN}+)\end{array}$} & \multirow[t]{3}{*}{66.2} & \multirow[t]{3}{*}{ CMF } & Median FU: 7.7 years & Total & 1,788 & & \multirow[t]{3}{*}{8} & \multirow{3}{*}{$\begin{array}{l}\text { Age, size, nodal } \\
\text { status, vessel } \\
\text { invasion, and } \\
\text { institution }\end{array}$} \\
\hline & & & & & & & DFS, 0.88 (0.76-1.03) & $<21$ days & 599 & $\begin{array}{l}5-y r \text { DFS } \\
62 \% ; 10-y r \\
\text { DFS } 51 \%\end{array}$ & & \\
\hline & & & & & & & Reference & $\geq 21$ days & 1,189 & $\begin{array}{l}5-y r \text { DFS } \\
57 \% ; 10-y r \\
\text { DFS 42\% }\end{array}$ & & \\
\hline \multirow{4}{*}{$\begin{array}{l}\text { Kerbrat, et al. } \\
\text { [5] } 2005^{*}\end{array}$} & \multirow{4}{*}{$\begin{array}{l}\text { France } \\
\text { (Retros., FASG) }\end{array}$} & \multirow[t]{4}{*}{ NR } & \multirow[t]{4}{*}{ NR } & \multirow[t]{4}{*}{ Operable } & \multirow[t]{4}{*}{ NR } & \multirow[t]{4}{*}{ Anthr.-based } & Median FU: 9 years & Total & 2,602 & & \multirow[t]{4}{*}{7} & \multirow{4}{*}{$\begin{array}{l}\text { Multivariate } \\
\text { adjustment; adjusted } \\
\text { factors not reported }\end{array}$} \\
\hline & & & & & & & DFS, $0.85(0.65-1.05)^{\S}$ & $<28$ days & 1,614 & $\begin{array}{l}9-y r \text { DFS } \\
60 \%\end{array}$ & & \\
\hline & & & & & & & Reference & 28-42 days & 883 & $\begin{array}{l}9-y r \text { DFS } \\
58 \%\end{array}$ & & \\
\hline & & & & & & & & $>42$ days & 105 & $\begin{array}{l}9-y r \text { DFS } \\
49 \%\end{array}$ & & \\
\hline \multirow[t]{5}{*}{$\begin{array}{l}\text { Cold et al. [10] } \\
2005 \text { (I) }\end{array}$} & \multirow[t]{5}{*}{$\begin{array}{l}\text { Denmark } \\
(\mathrm{CT}, \mathrm{DBCG})\end{array}$} & $\begin{array}{l}53 \% \mathrm{pts} \\
<46 \mathrm{yr}\end{array}$ & \multirow[t]{5}{*}{ Mixed } & \multirow[t]{5}{*}{ Operable } & \multirow[t]{5}{*}{77.0} & Classical CMF & Median FU: NR & Total & 352 & & 6 & $\begin{array}{l}\text { Age, tumour size, } \\
\text { nodes status, }\end{array}$ \\
\hline & & $\begin{array}{l}43 \% \text { pts } \\
46-55 \mathrm{yr}\end{array}$ & & & & & Reference & $1-3$ wks & 58 & & & $\begin{array}{l}\text { histological type, } \\
\text { grade, hormone } \\
\text { receptor status, and }\end{array}$ \\
\hline & & $\begin{array}{l}3 \% \mathrm{pts} \\
>55 \mathrm{yr}\end{array}$ & & & & & OS, 0.929 (0.441-1.957) & 3-4 wks & 92 & & & adjuvant irradiation \\
\hline & & & & & & & OS, 1.549 (0.761-3.149) & $4-5$ wks & 75 & & & \\
\hline & & & & & & & OS, $1.588(0.856-2.948)$ & $5-13 w k s$ & 127 & & & \\
\hline Cold et al. [10] & Denmark & $40 \%$ pts & Mixed & Operable & 58.3 & CMF i.v. & Median FU: NR & Total & 6,065 & & 8 & Age, tumour size, \\
\hline & $(C 1, D B C G)$ & $\begin{array}{l}<46 \mathrm{yr} \\
40 \% \mathrm{pts}\end{array}$ & & & & & Reference & $1-3$ wks & 1,509 & & & $\begin{array}{l}\text { nodes status, } \\
\text { histological type, }\end{array}$ \\
\hline & & $46-55 \mathrm{yr}$ & & & & & OS, 1.021 (0.903-1.155) & 3-4 wks & 1,581 & & & grade, hormone \\
\hline & & $\begin{array}{l}20 \% \mathrm{pts} \\
>55 \mathrm{yr}\end{array}$ & & & & & OS, $0.890(0.782-1.012)$ & $4-5$ wks & 1,423 & & & adjuvant irradiation \\
\hline & & & & & & & OS, $1.002(0.884-1.136)$ & 5-13 wks & 1,552 & & & \\
\hline
\end{tabular}


Table 1 Characteristics of eligible studies on waiting time to adjuvant chemotherapy and survival in breast cancer (Continued)

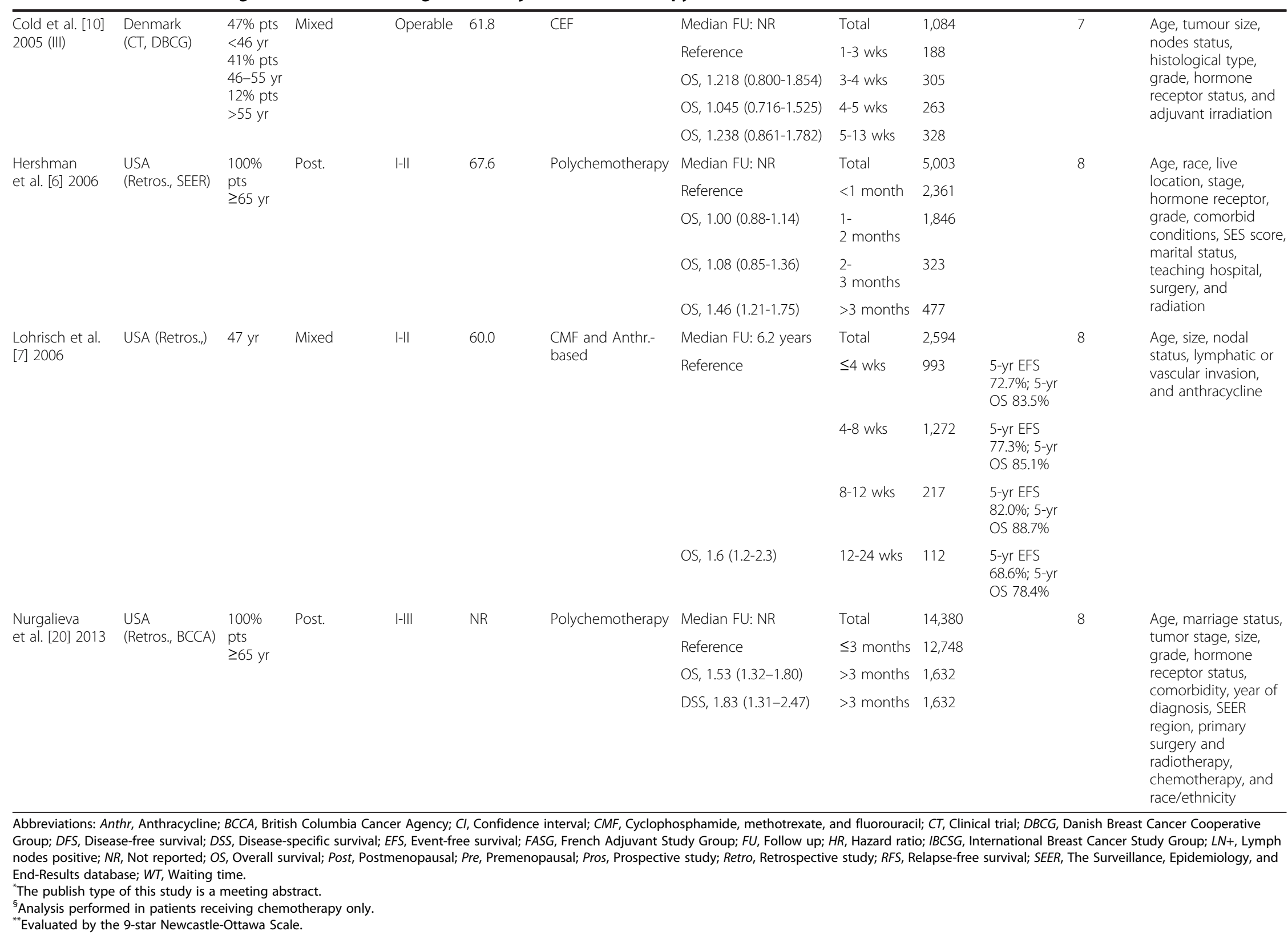

* Evaluated by the 9-star Newcastle-Ottawa Scale. 


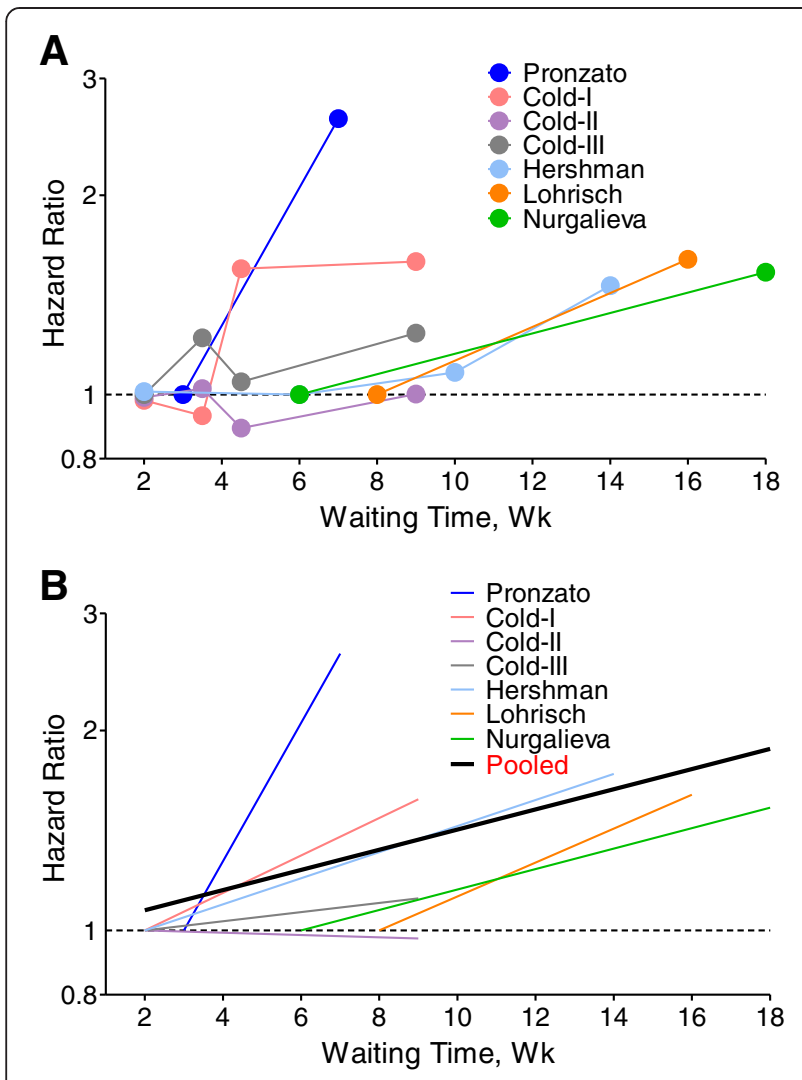

Figure $\mathbf{2}$ Individual hazard ratio for overall survival according to waiting time categories. A. The relationship between waiting time categories and overall survival in the 7 independent analytical groups. The hazard ratio (HR) represents a comparison with the lowest waiting time category in each study (as reference). The first author of each study is shown. B. Conversion of HR estimates from the original studies to an HR per week of delay. The slope of each line represents the change in the log HR per week delay. The line for each individual study is located over the range of waiting times. The thick line indicates the weighted average of the HRs from the individual studies. The vertical axis is on a log scale.

Figure 3A presents the forest plot of meta-analysis for OS, including HRs and 95\% CIs per 4-week of delay for 7 analytical groups. The combined HR was 1.15 (95\% CI, 1.03-1.28; $\mathrm{P}=0.009)$ by random-effects model. There was statistically significant heterogeneity between studies of OS ( $\left.\mathrm{P}<0.001 ; \mathrm{I}^{2}=75.4 \%\right)$. To explore the resource of heterogeneity, we performed influence analysis, which omits one study at a time and calculates the recombined HRs for the remainders. It showed that the Cold-II study by Cold et al. [10] substantially influenced the pooled HR (Figure 3B). After excluding that single study, there was no between-study heterogeneity $\left(\mathrm{P}=0.257 ; \mathrm{I}^{2}=23.6 \%\right)$, and the $\mathrm{HR}$ was more significant $(\mathrm{HR}=1.17 ; 95 \% \mathrm{CI}$, 1.12-1.22; $\mathrm{P}<0.001$; fixed-effects model). To further test the robustness of our study, we alternatively removed 2 studies with the largest weight and recalculated a combined HR estimate from the remaining studies, consistent and statistically significant results were maintained. The HR after removal of the Cold-II study by Cold et al. [10] (25.08\% weight) and the study by Nurgalieva et al. [20] (26.09\% weight) was 1.23 (95\% CI, 1.12-1.34; fixed-effects model) without evident heterogeneity either $\left(P=0.284, \mathrm{I}^{2}=20.5 \%\right)$. The funnel plot was used to evaluate publication bias and the Egger's test showed no evidence of publication bias $(\mathrm{P}=0.351)$.

The analyses were repeated for DFS (forest plot shown in Figure 4). The relevant 2 studies included 4,390 breast cancer patients. The combined HR was 1.16 (95\% CI, 1.01-1.33; fixed-effects model), without evidence of heterogeneity $\left(\mathrm{P}=0.623, \mathrm{I}^{2}=0.0 \%\right)$.

\section{Discussion}

Adjuvant chemotherapy (AC) has been admitted as the standard treatment for most breast cancer patients. However, the exact time frame of AC treatment initiated post-surgery to gain maximal benefit still remains unclear. The published clinical trials do not specifically suggest the timing of chemotherapy after surgery, and there is a wide variation across trials in the allowed time between surgery and $\mathrm{AC}$, ranging from 2 to 12 weeks [21-24]. It is unlikely that there will be additional prospective clinical trials comparing outcomes for AC initiation before or after a specified time (not perioperative) from surgery. Therefore, we have to rely on retrospective data as reviewed in this study. In this report, the systematic review and meta-analysis indicate that OS decreases by $15 \%$ for every 4 -week delay in initiation of AC. Our results are also consistent across DFS analysis. This present study is the first fully-reported meta-analysis specifically addressing the effect of a delay in time to $\mathrm{AC}$ on survival outcomes in breast cancer in a quantitative way.

The effect of AC on survival is thought to be eradication of micrometastatic deposits in a proportion of patients. There is a substantial theoretical rationale to initiate AC immediately after curative surgery. Investigation in animal models has demonstrated that surgery may increase the numbers of circulating tumor cells and oncogenic growth factors, and accelerate growth of metastases [25,26]; a single dose of chemotherapy given early seemed more efficient than treatment given later [27]. Biological plausibility, clinical observations, and published studies have brought up a comprehensive hypothesis that early initiation of $\mathrm{AC}$ is clinically crucial to patient's survival.

The available evidence that describes a relationship between time to AC and patient outcomes is shown in Table 1. In other relevant studies of association between time to AC and survival but not included in this metaanalysis due to low validity, inconsistent results were presented. Studies by Buzdar et al. [28], Shannon et al. [29], Samur et al. [4], and Sanchez et al. [30] failed to show 

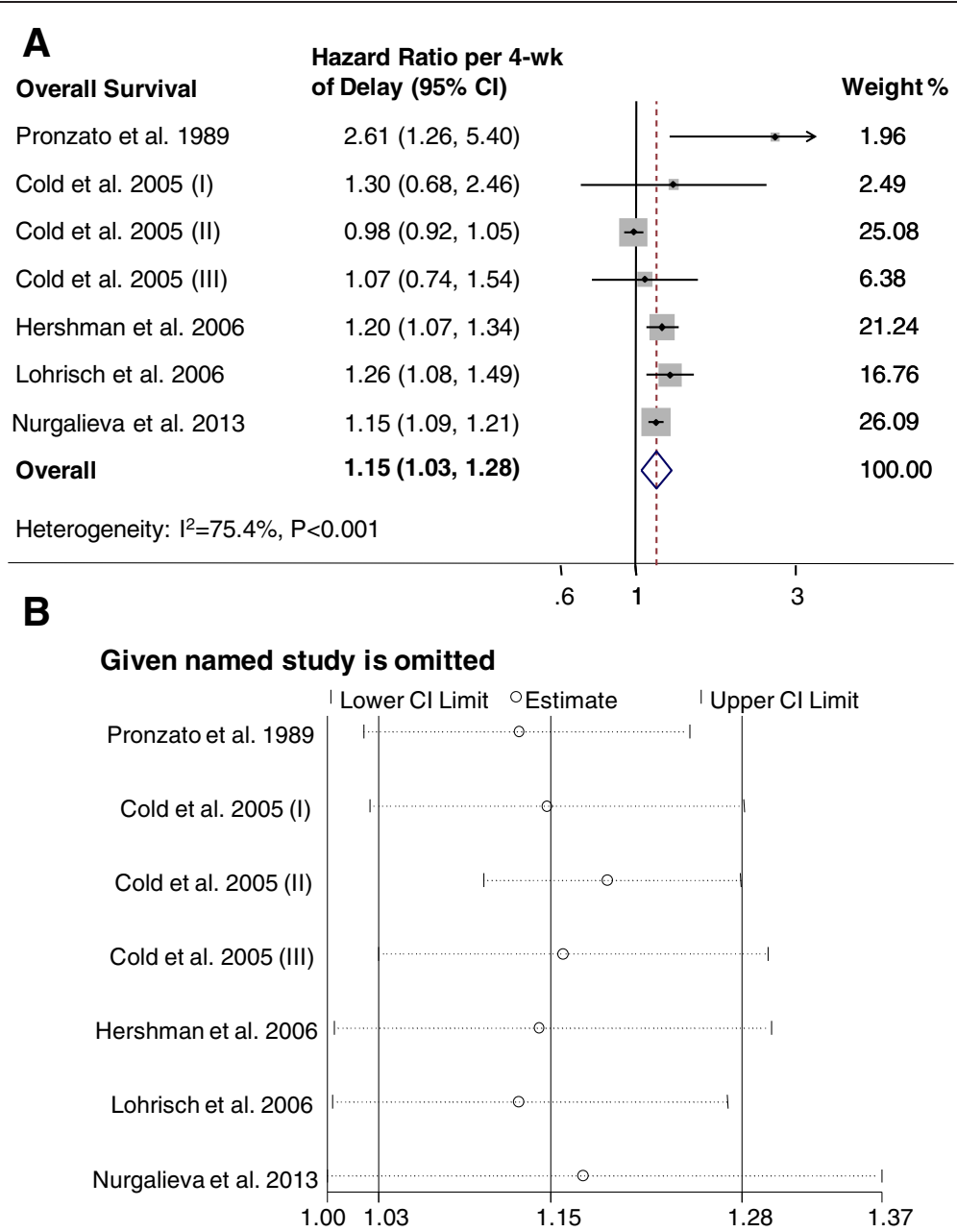

Figure 3 Individual study and overall hazard ratios of relationships between every 4-week delay in initiation of adjuvant chemotherapy and overall survival. Individual and overall hazard ratios (HR) per 4-week of delay with 95\% confidence interval (Cl) for OS are shown in $\mathbf{A}$. The size of each square is proportional to the weight of the study. For the combined result, the length of the diamond represents the $95 \% \mathrm{Cl}$ of the summary. B. shows the influence of individual studies on the pooled HR. The vertical axis indicates the overall HR and the two vertical axes indicate its $95 \% \mathrm{Cl}$. Every hollow round indicates the pooled OR when the left study is omitted in this meta-analysis. The two ends of every broken line represent the respective $95 \% \mathrm{Cl}$.

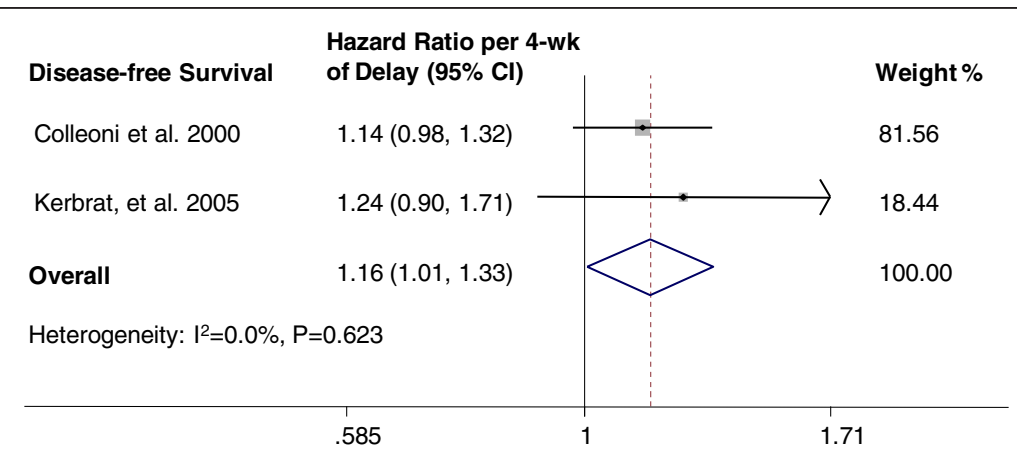

Figure 4 Individual study and overall hazard ratios of relationships between every 4-week delay in initiation of adjuvant chemotherapy and disease-free survival. Individual and overall hazard ratios (HR) per 4-week of delay with 95\% confidence interval (Cl) for DFS is shown. The size of each square is proportional to the weight of the study. For the combined result, the length of the diamond represents the $95 \% \mathrm{Cl}$ of the summary. 
inferior outcome for chemotherapy started later after surgery compared with chemotherapy stared early. In contrast, Alkis et al. [31] reported that OS was significantly better in patients who started AC within 44 days. Brooks et al. [32] also exhibited an improvement in DFS for patients with node-positive cancers receiving $\mathrm{AC}$ within 4 weeks compared with those patients receiving delayed chemotherapy. Another Turkish study [33] argued that the upper limit of time to initiation of AC could be up to 4.8 months. We did not included all the aforementioned studies [4,28-33] since none of them have provided sufficient data to calculate an adjusted and quantitive HR for meta-analysis. Biagi et al. [34] also performed a similar meta-analysis and demonstrated that a 4-week increase in time to adjuvant chemotherapy was associated with a significant OS HR of 1.06 (95\% CI 1.02-1.10) and DFS HR of 1.08 (95\% CI 1.03-1.14) in breast cancer. However, that study published abstract only in ASCO 2011, and there was a statistical flaw because the authors combined individual studies using a fixed-effect model although there was an obvious inter-study heterogeneity.

Our meta-analysis demonstrates an evident association between delayed AC and poor OS. However, there was a significant heterogeneity between studies for OS. By influence analysis, a study (Cold-II) based on clinical trial data [10] seemed to be a major resource of heterogeneity. After removing that single study, the heterogeneity disappeared and the association was more significant. The disparate results before and after removing the Cold-II study [10] may be due to the relative short waiting times of that study (all the patients from controlled trials and received $\mathrm{AC}$ within 3-months after surgery), patient selection bias (women with delayed AC could not be enrolled in original trials), inappropriate category classification (investigator grouped the patients into 1-3 weeks, 4 weeks, 5 weeks, and 613 weeks group; such short intervals make detection of significance difficult), and possibly, the cycle numbers of chemotherapy (they used CMF i.v. on day 1, every 3 weeks, 9 times; while classical CMF used on days 1 and 8, every 4 weeks, 12 times).

Applying our findings to a patient who is ready to initiate $\mathrm{AC}$ at 4 weeks after surgery but is actually delayed, this patient would have a $15 \%$ increased risk of mortality if treated at 8 weeks and $32.25 \%$ increased risk at 12 weeks. According to the updated EBCTCG report, 36\% reduction in breast cancer mortality rate can be achieved for AC versus no AC at 10-year [1]. We may reckon that, in general, breast cancer patients should start AC with no more than 8-week delay of the planned initiation which is probably within 4 weeks after surgery. However, for the high-risk patients with young age and ER-negative tumor, individualized strategy of AC initiation should be applied according to relevant study [9]. Although our analysis may over- or under-estimate the effect of delayed time on survival, we believe these results should help to modify protocols for those agencies that carry breast cancer cares and services.

Some limitations should be declared. First, our metaanalysis is limited by the nonrandomized and retrospective nature of the included studies. However, it is unrealistic to expect that a randomized trial of time to AC will ever be done; rather, analyses such as ours are likely to provide the only evidence of such an effect. Hence we believe that our results, coupled with preclinical models and relevant clinical evidence, have provided sufficient proof of a substantial reverse relationship between prolonged waiting times to initiation of $\mathrm{AC}$ and reduced survival. Second, there should be other prognostic factors not controlled in the meta-analysis. The number of cycles, completion rate for $\mathrm{AC}$, dose reduction, using endocrine therapy or not, and HER2 status, which were considered as key determinants of survival, are not always adjusted in the eligible studies. The effect of AC delay on survival might vary in patients with different clinicopathological features. However, because of a lack of individual information of patients, we failed to do sub-analyses according to different features. Third, at least $57 \%$ of all the study patients (according to Hershman's [6] and Nurgaliev's [20] studies) were older than 65 years. The different age distribution of the patients between this study and general breast cancer population (median age is 55 years according to SEER database [35]) might have potential impacts on the conclusion. Fourth, our study relies on the assumption of a log-linear relationship for the effect of waiting time on survival. However, the assumption of linearity to this relationship might be problematic sometimes. For instance, a few studies showed that survivals were similar for patients if they started AC within 12 weeks after surgery, and only those starting $\mathrm{AC}$ at later than 12 weeks had significantly inferior survival $[6,7]$. Since a linear relationship may unfit the first 12 weeks, the regressed summary HR across the whole time frame may not reflect the real effect. Finally, since most included studies used CMF and anthracyclinebased regimen, whether the results of meta-analysis can be extrapolated to the current taxane era is unclear. Albeit this, our findings might potentially have broad clinical relevance. Since removal of a primary tumor would enhance the growth of metastasis [26,36], it is plausible that early intervention of conventional cytotoxic agents (anthracycline, cyclophosphamide, methotrexate, etc.) would exert a better tumor suppressive effect. Comparing with classic cytotoxic agents, taxanes are more effective on cells in division and growth since they are microtubule inhibitors that bind reversibly to the subunit of tubulin and lead to cell arrest at the G2/M phase of the cell cycle. It is reasonable to speculate that early initiation of taxane-containing chemotherapy may be particularly effective on inhibiting the cancer cells in mitotic phase caused by surgery stress. 


\section{Conclusion}

Our results demonstrate a significant adverse association between waiting time to AC initiation and survival in breast cancer. The results also provide further validation of the intuitive concept of early time to AC after surgical treatment. Physicians may need to give more careful consideration to timing when discussing AC with patients, and clinicians and jurisdictions need to optimize the patient flow logistics to minimize the interval from surgery to AC.

\section{Competing interest}

The authors have declared that no competing interests exist.

\section{Authors' contributions}

YKD, HS, ZJX, LGY and SZM drafted the manuscript. YKD, HS, and ZJX participated in data collection and analysis. YKD, HS, and SZM participated in data interpretation. YKD and SZM participated in the conception and design of the study. YKD designed the general study. All authors reviewed and approved the final manuscript.

\section{Acknowledgement}

This research is supported by grants from the National Natural Science Foundation of China $(81001169,81102003)$, the Shanghai United Developing Technology Project of Municipal Hospitals (SHDC12010116), the Key Clinical Program of the Ministry of Health (2010-2012), the Zhuo-Xue Project of Fudan University (For Y.K.D.), and the Shanghai Committee of Science and Technology Fund for 2011 Qimingxing Project (11QA1401400, for Y.K.D.). The funders had no role in the study design, data collection and analysis, decision to publish, or preparation of the manuscript.

Received: 11 May 2013 Accepted: 13 May 2013

Published: 16 May 2013

\section{References}

1. Peto R, Davies C, Godwin J, Gray R, Pan HC, Clarke M, Cutter D, Darby S, McGale P, Taylor C, et al: Comparisons between different polychemotherapy regimens for early breast cancer: meta-analyses of long-term outcome among 100,000 women in 123 randomised trials. Lancet 2012, 379(9814):432-444.

2. Goldhirsch A, Wood WC, Coates AS, Gelber RD, Thurlimann B, Senn HJ: Strategies for subtypes--dealing with the diversity of breast cancer: highlights of the St. Gallen International Expert Consensus on the Primary Therapy of Early Breast Cancer 2011. Ann Oncol 2011, 22(8):1736-1747.

3. Fedewa SA, Ward EM, Stewart AK, Edge SB: Delays in adjuvant chemotherapy treatment among patients with breast cancer are more likely in African American and Hispanic populations: a national cohort study 2004-2006. J Clin Oncol 2010, 28(27):4135-4141.

4. Samur M, Bozcuk HS, Dalmaz G, Karaveli S, Köseoğlu FG, Colak T, Pestereli E: Treatment delay in breast cancer; does it really have an impact on prognosis? Turk J Canc 2002, 32(4):138-147.

5. Kerbrat $P$, Roche $H$, Fumoleau $P$, Bonneterre J, Romestaing $P$, Fargeot $P$, Namer M, Monnier A, Montcuquet $P$, Goudier M, et al: Does time interval between surgery and adjuvant chemotherapy initiation modify treatment efficacy in operable, breast cancer patients? French Adjuvant Study Group (FASG) Results. J Clin Oncol 2005, 23(16S):660.

6. Hershman DL, Wang X, McBride R, Jacobson JS, Grann VR, Neugut Al: Delay of adjuvant chemotherapy initiation following breast cancer surgery among elderly women. Breast Canc Res Treat 2006, 99(3):313-321.

7. Lohrisch C, Paltiel C, Gelmon K, Speers C, Taylor S, Barnett J, Olivotto IA: Impact on survival of time from definitive surgery to initiation of adjuvant chemotherapy for early-stage breast cancer. J Clin Oncol 2006, 24(30):4888-4894.

8. Pronzato P, Campora E, Amoroso D, Bertelli G, Botto F, Conte PF, Sertoli MR, Rosso R: Impact of administration-related factors on outcome of adjuvant chemotherapy for primary breast cancer. Am J Clin Oncol 1989, 12(6):481-485.
9. Colleoni M, Bonetti M, Coates AS, Castiglione-Gertsch M, Gelber RD, Price K, Rudenstam CM, Lindtner J, Collins J, Thurlimann B, et al: Early start of adjuvant chemotherapy may improve treatment outcome for premenopausal breast cancer patients with tumors not expressing estrogen receptors. The International Breast Cancer Study Group. J Clin Oncol 2000, 18(3):584-590.

10. Cold S, During M, Ewertz M, Knoop A, Moller S: Does timing of adjuvant chemotherapy influence the prognosis after early breast cancer? Results of the Danish Breast Cancer Cooperative Group (DBCG). Br J Canc 2005, 93(6):627-632.

11. DerSimonian R, Laird N: Meta-analysis in clinical trials. Contr Clin Trials 1986, 7(3):177-188

12. Larsson SC, Orsini N, Wolk A: Vitamin B6 and risk of colorectal cancer: a meta-analysis of prospective studies. JAMA 2010, 303(11):1077-1083.

13. Biagi JJ, Raphael MJ, Mackillop WJ, Kong W, King WD, Booth CM: Association between time to initiation of adjuvant chemotherapy and survival in colorectal cancer: a systematic review and meta-analysis. JAMA 2011, 305(22):2335-2342.

14. Yu KD, Di GH, Fan L, Wu J, Hu Z, Shen ZZ, Huang W, Shao ZM: A functional polymorphism in the promoter region of GSTM1 implies a complex role for GSTM1 in breast cancer. FASEB J 2009, 23(7):2274-2287.

15. Berlin JA, Longnecker MP, Greenland S: Meta-analysis of epidemiologic dose-response data. Epidemiology 1993, 4(3):218-228.

16. Johnson ES, Lanes SF, Wentworth CE, Satterfield MH, Abebe BL, Dicker LW: A metaregression analysis of the dose-response effect of aspirin on stroke. Arch Intern Med 1999, 159(11):1248-1253.

17. Higgins JP, Thompson SG: Quantifying heterogeneity in a meta-analysis. Stat Med 2002, 21(11):1539-1558.

18. Higgins JP, Thompson SG, Deeks JJ, Altman DG: Measuring inconsistency in meta-analyses. BMJ 2003, 327(7414):557-560.

19. Egger M, Davey Smith G, Schneider M, Minder C: Bias in meta-analysis detected by a simple, graphical test. BMJ 1997, 315(7109):629-634.

20. Nurgalieva ZZ, Franzini L, Morgan RO, Vernon SW, Liu CC, Du XL: Impact of timing of adjuvant chemotherapy initiation and completion after surgery on racial disparities in survival among women with breast cancer. Med Oncol 2013, 30(1):419.

21. Bonadonna G, Valagussa P, Moliterni A, Zambetti M, Brambilla C: Adjuvant cyclophosphamide, methotrexate, and fluorouracil in node-positive breast cancer: the results of 20 years of follow-up. N Engl J Med 1995, 332(14):901-906.

22. Henderson IC, Berry DA, Demetri GD, Cirrincione $C T$, Goldstein L, Martino S, Ingle JN, Cooper MR, Hayes DF, Tkaczuk KH, et al: Improved outcomes from adding sequential Paclitaxel but not from escalating Doxorubicin dose in an adjuvant chemotherapy regimen for patients with nodepositive primary breast cancer. J Clin Oncol 2003, 21(6):976-983.

23. Levine MN, Bramwell VH, Pritchard KI, Norris BD, Shepherd LE, Abu-Zahra H, Findlay B, Warr D, Bowman D, Myles J, et al: Randomized trial of intensive cyclophosphamide, epirubicin, and fluorouracil chemotherapy compared with cyclophosphamide, methotrexate, and fluorouracil in premenopausal women with node-positive breast cancer. National Cancer Institute of Canada Clinical Trials Group. J Clin Oncol 1998, 16(8):2651-2658.

24. French Adjuvant Study Group: Benefit of a high-dose epirubicin regimen in adjuvant chemotherapy for node-positive breast cancer patients with poor prognostic factors: 5-year follow-up results of French Adjuvant Study Group 05 randomized trial. J Clin Oncol 2001, 19(3):602-611.

25. Heppner $\mathrm{GH}$ : In vitro studies on cell-mediated immunity following surgery in mice sensitized to syngeneic mammary tumors. Int J Canc 1972, 9(1):119-125.

26. Fisher B, Gunduz N, Coyle J, Rudock C, Saffer E: Presence of a growthstimulating factor in serum following primary tumor removal in mice. Canc Res 1989, 49(8):1996-2001.

27. Fisher B, Gunduz N, Saffer EA: Influence of the interval between primary tumor removal and chemotherapy on kinetics and growth of metastases. Canc Res 1983, 43(4):1488-1492.

28. Buzdar AU, Smith TL, Powell KC, Blumenschein GR, Gehan EA: Effect of timing of initiation of adjuvant chemotherapy on disease-free survival in breast cancer. Breast Canc Res Treat 1982, 2(2):163-169.

29. Shannon C, Ashley S, Smith IE: Does timing of adjuvant chemotherapy for early breast cancer influence survival? J Clin Oncol 2003, 21(20):3792-3797.

30. Jara Sanchez C, Ruiz A, Martin M, Anton A, Munarriz B, Plazaola A, Schneider J, Martinez del Prado P, Alba E, Fernandez-Aramburo A: Influence of timing 
of initiation of adjuvant chemotherapy over survival in breast cancer: a negative outcome study by the Spanish Breast Cancer Research Group (GEICAM). Breast Canc Res Treat 2007, 101(2):215-223.

31. Alkis N, Durnali AG, Arslan UY, Kocer M, Onder FO, Tokluoglu S, Celenkoglu G, Muallaoglu S, Utkan G, Ulas A, et al: Optimal timing of adjuvant treatment in patients with early breast cancer. Med Oncol 2011, 28(4):1255-1259.

32. Brooks RJ, Jones SE, Salmon SE: Improved outcome with early treatment in an adjuvant breast cancer program. Proc Am Soc Clin Oncol 1983, 2:110.

33. Altundag MK, Celik I, Ozisik Y: Is there a range of time for initiation of adjuvant chemotherapy in patients with malignancy? Ann Oncol 2000, 11(9):1209.

34. Biagi JJ, Raphael M, King WD, Kong W, Booth CM, Mackillop WJ: The effect of delay in time to adjuvant chemotherapy (TTAC) on survival in breast cancer (BC): A systematic review and meta-analysis. J Clin Oncol 2011, 29(suppl):abstr 1128.

35. Yu KD, Jiang YZ, Chen S, Cao ZG, Wu J, Shen ZZ, Shao ZM: Effect of large tumor size on cancer-specific mortality in node-negative breast cancer. Mayo Clin Proc 2012, 87(12):1171-1180.

36. Folkman $\mathrm{J}$ : What is the evidence that tumors are angiogenesis dependent? J Natl Canc Inst 1990, 82(1):4-6.

doi:10.1186/1471-2407-13-240

Cite this article as: Yu et al:: Association between delayed initiation of adjuvant CMF or anthracycline-based chemotherapy and survival in breast cancer: a systematic review and meta-analysis. BMC Cancer 2013 13:240.

\section{Submit your next manuscript to BioMed Central and take full advantage of:}

- Convenient online submission

- Thorough peer review

- No space constraints or color figure charges

- Immediate publication on acceptance

- Inclusion in PubMed, CAS, Scopus and Google Scholar

- Research which is freely available for redistribution 